\title{
The Influences of the Policies in Different Countries on the Containing of COVID-19
}

\author{
Jierong Zhang \\ Tsing Hua high School International Chaoyang, Beijing, 100192, China \\ Corresponding author's e-mail: Vivian.wang @ cas-harbour.org
}

\begin{abstract}
COVID-19 is one of the huge disasters in this year. Millions of people have died in this epidemic. This paper introduced the different policies in America, Italy, and China that were used to control the COVID-19, and analyze the different cultural background, economic conditions, as well as political structures and systems. Observation and data comparison are used to create a full timeline of the policies and their effects. Different countries have different economy, political structures, and systems. With these differences, the control to the virus also differs, for example, in America, the most effective lockdown policy will not work long in this country, since not all people in America have the concept of saving. Countries like China took a lot of money to control people movement due to its population density. According to the results of this paper showed that the lockdown is the most effective policy, whereas, the extent of disadvantage in different countries also differs from each country, which go beyond author's hypothesis of lockdown policy.
\end{abstract}

Keywords: Covid-19, policies, cultural background, Italy, USA, China

\section{INTRODUCTION}

The world had a bad start in 2020: Disasters from last year did not stopped yet, while new crisis comes out one after one. Undoubtedly, the corona virus must be the greatest conjecture among all those crises over the world in 2020. Started in China in December 27th, 2019 in Wuhan, China, with first patient found in the South China Seafood Market, the war against the novel corona virus COVID-19 began. Nowadays, the virus has spread to at least 60 countries over the world, infecting over 1 million people. The attitudes of people and government of different countries are various at the beginning of the epidemic situation. With only a few countries realize the danger of the virus, the world becomes a mess. The outbreak of virus in China is lethal. Countries around China start to take effective actions. The death toll and diagnosed cases in some countries are increasing in a surprising speed compared to other countries. The difference in policy must have impact on the situation.

Hence, the primary target of this essay is to find out the differences in policies or measures for containing the epidemic, and find out to what extent the policy exerts influence on the infection of people.

This paper chose America, China and Italy as study objects. Since these are the 3 countries that had serious outbreak at the beginning of their situation. The author focused on the policy of controlling the outbreak of each country, for instance, the propagandization of the danger of the virus and the NAT (nucleic acid testing) to people.

The fact that some countries' death number and infection number are increasing in a surprising speed comparing to other countries. The different in policy must have impact on the situation. Hence, the primary target of this essay is to find out the different policy or action in controlling the epidemic situation and find out to what extent the policy has influence on the infection of people. As the analysis came out, this can give the citizens of out-breaking countries a clear concept of what policy would work, and what role can they play in controlling the virus.

\section{METHOD}

This paper collected the data of infection and action that different countries took in order to see the impact. However, there is a problem about the method, that there is no standard of the "extent" and the exact policy that really has influence on the infection number, so the author is going to find out the common point of policies or measures that different countries have taken to find out the effective measure, thus defining the standard using the specific number of infection. The data are collected in a timeline form from February 1st to April 1st. America, Italy, and China are selected as samples and they were collected from a database called Worldometers. It has relative accurate infected patients of all countries that has corona virus patients. The possible sources are news and official sites of the country that would post relevant actions they took. A graph of daily increment of patients of certain period for selected countries is created. By observing when the country has a huge leap on the patient number and match with the information of official site of the country that records what happened that day, the author will be able to see which certain policy has effect to the situation. A timeline of the policy and the data would discover the essential one that really help them to control the patient number. 


\section{RESULTS}

The author will start from America, where there are the most patients.

\subsection{The epidemic situation in America}

These are the data of the daily new cases in the America over the last 2 months.

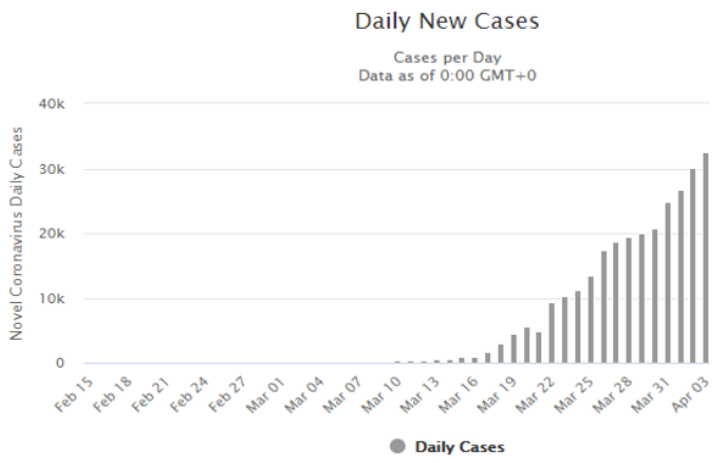

Figure 1. Daily new cases of America from Feb. 15 to Apr. 03.

From the Figure 1, it can be seen that the cases burst in March. The cases increase in an exponential speed: It took America 20 days for the number break through 10000/day from 100/day[2]. Suggesting that the virus has spread over the country. Problems about measures for the virus happened during this period. The news from Demcracynow showed that America shut down its border on March 20th, that is when the total patients meet the number 20000[2]. When the virus first appears in America, the government and CDC warned people the danger of going out and the necessity of wearing masks. This action was taken at January, and from the graph the readers know that it is not working effectively. Another action the America took is the shutdown of public facilities. News from Vox in March 13rd mentioned that America is shutting down. It does contribute to the cases, since the tendency of that time is increasing in a relative slow speed, about 1000 cases/day[2].

\subsection{The epidemic situation in Italy}

This is the data of the daily new cases in the Italy over last 2 months.

\section{Daily New Cases}

Cases per Day

Data as of 0:00 GMT+0

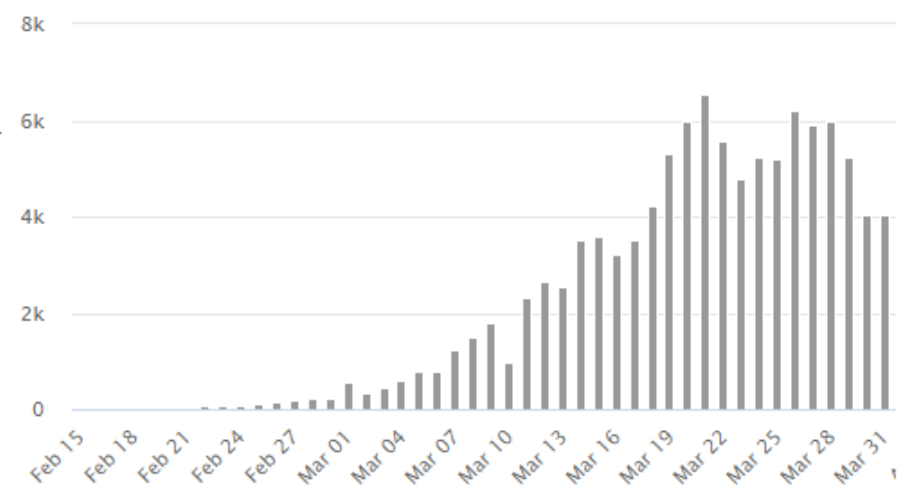

Figure 2. Daily new cases of Italy from Feb. 15 to Mar. 31.
The number of new cases is increasing from February and meet a peek at about March 21, then it starts to decreasing[2]. The outbreak of the coronavirus in the European and Americas happens mainly happens in March. Having the information of what Italy did to stop the spread of the coronavirus over the country from Axios and Livescience, Italy stopped flights from China since January, partially containing the outspread of the Covid-19 did partially job for stopping coronavirus. However, it did not stop the virus from attacking the whole country. Italy had to set up enforcement policies like shutting down restaurant and schools to alleviate the situation. What they finally did was to shut down the factories and working places on March 22 th in order to reduce the outgoing population[3]. The action did work for the Italy, and the new cases of Italy did decline on March 22th[3]. 


\subsection{The epidemic situation in China}

This is the data of the daily new cases in China over the last 2 months.

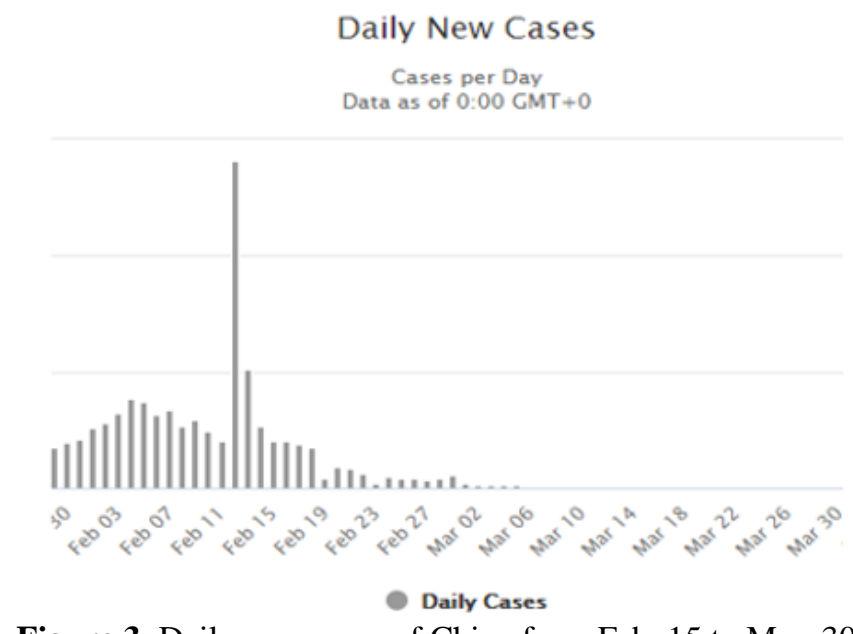

Figure 3. Daily new cases of China from Feb. 15 to Mar. 30.

By looking at the tendency of the graph, people are able to tell that the daily new cases increase in a constant speed from February 1st to mid-month and starts decreasing then, except for several days of sudden explosion of patients[2]. By just observing the tendency, it is clear that there must be some actions that control the outbreak[2]. According to the news, China shut down the outbreak place, Wuhan, which restricted the possible exponential spread of the new cases. According to the data of National Commission, the major infection cases are all in Wuhan, where it has over 60000 patients over a total of 80000 cases in China[6]. With the order of shutting down, the control on the virus becomes really easy. This is the reason that the curve of the daily newly cases start to decrease after the shutting down Wuhan for about 2 months.

The enforcements are more useful than just giving advices. Shutting down transportation from possible infected countries did help with restriction, however, it needs to be fast. Countries like Singapore did a good job in refusing travelers from China, that saved the whole country from Corona virus[5]. Clearly shutting down the cities that have most infections and enhancing the detection strength is really useful in stopping the spread of the virus. Giving advice to public is not that effective at the start of the outbreak. A lot of people refuse to wear masks at the early period of the outbreak[5]. They do not know the horror of the virus, but as people dies near them and the number of deaths increase in a shocking speed, they start to feel panic. The advices become useful at this time. The more awareness to the virus, the lower the cases. Everyone in China understands the horror of the corona virus. Italy's people start to understand how terrible this virus is as they found that too many people are dying, that they found people surround them are dying, and they will die soon if they don't take any measures. Some states in America successfully locked their citizens in their house, and people are understanding that they will die if everyone live as normal life without any protections, and yet the situation is still very tough.

\section{DISCUSSION}

The most powerful mean the media is needed to influence the public's thoughts to the virus rather than relieve the public's nervous mind. People will cooperate with the policy as they know how dangerous the virus is, since this is creature's instinct of survive. China did a really good job on the media part. They created a real-time data graph and put it on every kind of media, including explorer, video apps, and Television, which spread to a wide range of people. The number on the data graph did warn people, and the author really felt the tension within a week. The horror of the virus was understood by citizens.

Shutting down a huge metropolis that has the most infections is the most effective way to deal with the virus, but the fact is that a lot of countries are not able to do the same thing as China. According to the National Stats, Wuhan lost about 20 billion RMB in the Q1 of 2020[4]. The data of the National stats showed that the GDP of Wuhan in 2017 is 1341.04 billion RMB, and 1484.72 billion in 2018[5]. This is the approximate amount of the difference in total year GDP of 2018 and 2017. Clearly it will be a wound to Wuhan itself. China is a collectivism country, it can always unite as a whole, which means that people are willing to sacrifice their benefits for the whole country. This is the difference from root. Also, the economic structure of China is very different from other countries. People in China have the habit of saving a huge amount of money for themselves to use in the future, and they usually don't have huge debt to pay back, which means that when it comes to emergency like lockout, people in China are able to live more times than other countries[8]. However, the shortcoming is also tremendous, in China, some small shops and restaurant that needs maintenance and a lot of workers 
are closed because of the virus, and the saving of the boss of the small commercial tenant is not enough to support the whole team. The policy's impact is too wide that the economic in China was affected in a negative direction. However, the fact is that a lot of countries' citizens don't have the habit of saving and unity when it comes to a crisis, which means that they are not able to achieve the policies similar to China. The result will be clear if the government of other countries use similar policies like China.

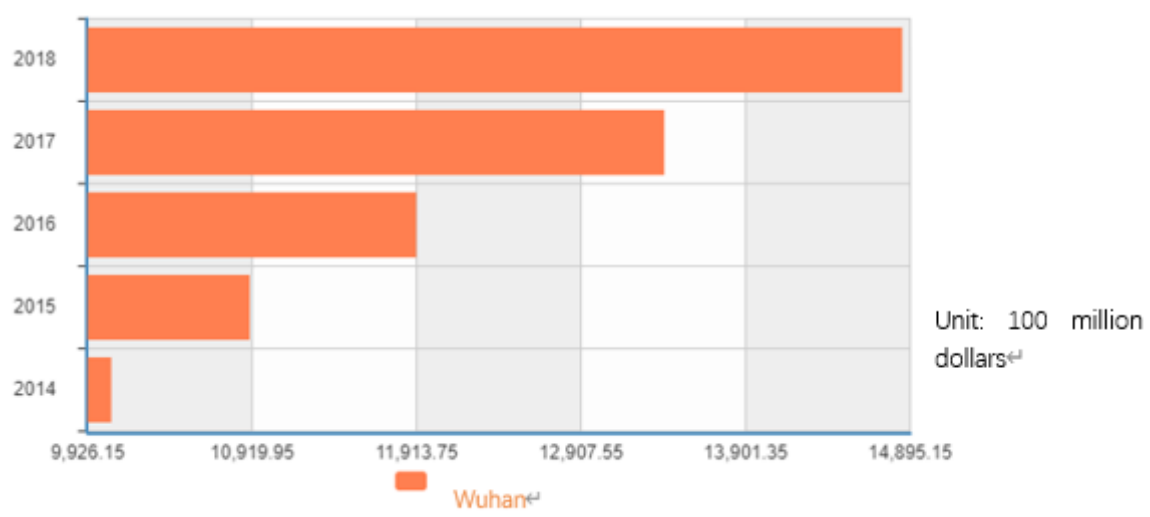

Figure 4. GDP of Wuhan over last 5 years.

Not only in China, America and other developed countries' small airlines are facing a huge problem, since they do not have passengers due to the virus, and their planes and facilities need maintenance. They will bankrupt eventually if the situation can't revive in a short term [5]. The fact is that it is impossible for the country to recover in a short period[5]. The same thing also happened in China in 2003, the SARS [5]. A lot of airlines have to live with government's help, and this is almost impossible for a lot of countries to achieve. Some states of America did stopped working, whereas the number of unemployment people is climbing in a striking speed, indicating about 10 million people has lost their jobs, which is really bad. People will die without money in this society, but working outside means that their probability of getting coronavirus increases. With the time past, the damage of every country will become larger.

\section{CONCLUSION}

The results of the policies are various. It is clear that no matter what policies the country implements, the enforcements like lockdown policies are really effective. Besides, the widespread of information about the coronavirus via media will also has effects on people's selfprotection awareness. People survived due to the lockdown, a lot of internet-related apps found their market in this situation, but the economy was hurt badly, and a lot of people lost their jobs, and some are not able to find another new job.

Because the limited data sources, the results are also limited, with only observations used to connect the data with the policies, but it is also useful in getting all the data.

\section{ACKNOWLEDGMENT}

First and foremost, I would like to show my deepest gratitude to my teachers and professors in my university, who have provided me with valuable guidance in every stage of the writing of this thesis. Further, I would like to thank all my friends and roommates for their encouragement and support. Without all their enlightening instruction and impressive kindness, I could not have completed my thesis.

\section{REFERENCES}

[1] World Health Organization, 1 April 2020. Accessed on April 1, 2020.https://covid19.who.int/.

[2] Worldometer, April 1, 2020. Accessed on April 1, 2020.https://www.worldometers.info/coronavirus/?.

[3] Dave Lawler, "Timeline: How Italy's coronavirus crisis became the world's deadliest", Axios, May 24, 2020. Accessed on April 2, 2020. https://www.axios.com/italycoronavirus-timeline-lockdown-deaths-cases-2adb0fc76ab5-4b7c-9a55-bc6897494dc6.html.

[4] National Data, http://data.stats.gov.cn/ Accessed on April 2, 2020.

[5] "The News Studio", CCTV 13 
[6] "Real-time big data reporting on the epidemic", Baidu, https://voice.baidu.com/act/newpneumonia/newpneumonia /?from=osari_pc_3, Accessed on April 4, 2020.

[7] "Japan GDP Growth Rate", trading economics, https://tradingeconomics.com/japan/gdp-growth, Accessed on April 4, 2020

[8] "Why Chinese love saving?" Zhihu, https://www.zhihu.com/question/20349453, Accessed on June 14, 2020 